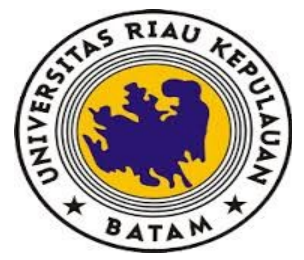

Available online at www.journal.unrika.ac.id

Jurnal KOPASTA

Jurnal KOPASTA, 3 (1), (2016) 9-13

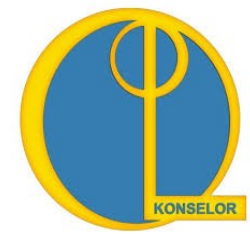

\title{
PELAKSANAAN LAYANAN INFORMASI DENGAN MOVIE MAKER DALAM MENINGKATKAN SELF REGULATED LEARNING
}

\author{
Sri Wahyuni Adiningtyas* \\ Division of Counseling and Guidance, University, of Riau Kepulauan, Batam
}

\begin{abstract}
Abstrak
Artikel ini membahas kurangnya pengaturan diri siswa dalam belajar (self regulated learning), di mana hal tersebut dapat berpengaruh negatif pada kualitas dan kuantitas pembelajaran. Bimbingan dan konseling dengan segenap pelayanannya mempunyai tugas dan peran dalam meningkatkan pengaturan diri dalam belajar pada siswa, salah satunya dengan layanan informasi. Dengan mengadakan layanan informasi, siswa akan diberikan pemahaman dan pengetahuan dalam meningkatkan pengaturan diri dalam belajar. Implikasinya terhadap bimbingan dan konseling untuk meningkatkan pengaturan diri dalam belajar pada siswa melalui layanan informasi dengan movie maker terkait pentingnya kemandirian dalam belajar dan gaya belajar, agar siswa tidak jenuh dalam belajar disarankan kepada guru BK untuk dapat melaksanakan layanan informasi dengan movie maker secara berkelanjutan atau lebih terencana untuk lebih meningkatkan pengaturan diri dalam belajar pada siswa.
\end{abstract}

Keywords: Pengaturan Diri dalam Belajar, Layanan Informasi

\section{Pendahuluan}

Pendidikan mempunyai peran yang amat penting bagi perkembangan dan perwujudan diri individu, terutama bagi pembangunan bangsa dan negara. Pendidikan pada hakekatnya bertujuan agar para siswa dapat mencapai perkembangan yang optimal sesuai dengan potensi diri, kemampuan dan nilai pribadinya (Semiawan, 2000:45), sesuai dengan Undang-Undang Nomor 20 Tahun 2003 tentang Sistem Pendidikan Nasional. Bimbingan dan konseling merupakan salah satu komponen dari sistem pendidikan, mengingat bahwa bimbingan dan konseling adalah suatu kegiatan bantuan dan tuntunan yang diberikan kepada individu pada umumnya dan pada siswa khususnya di sekolah dalam rangka meningkatkan mutunya.

Sekolah sebagai lembaga pendidikan formal memegang peranan dan bertanggung jawab dalam menunjang keberhasilan siswa untuk menjalankan tugas-tugas perkembangannya dengan baik. Sejalan dengan hal tersebut layanan informasi mempunyai fungsi utama yaitu fungsi pemahaman dan fungsi pencegahan maksudnya bahwa dengan layanan informasi tersebut, individu memiliki pemahaman yang lebih terhadap berbagai hal tentang kehidupan, sehingga dirinya dapat terhindar dari pola hidup yang tidak benar.

Setiap individu memiliki kemampuan untuk mengatur diri, hanya saja kemampuan mengatur diri setiap individu berbeda-beda. Kemampuan mengatur diri ini dikenal dengan self regulation. Self regulation ini penting

*Sri Wahyuni Adiningtyas Telp.083182820008 E-mail address: sriwayunia3@gmail.com 
bagi setiap individu terutama siswa dalam proses belajarnya, dengan self regulation yang baik, hidup akan lebih teratur dan terarah sehingga individu dapat mencapai hasil belajar yang optimal. Apabila individu memiliki self regulation yang baik maka individu dapat mengontrol dirinya sendiri dengan baik. Pengaturan diri dalam belajar disebut juga dengan Self regulated learning mencakup kemampuan strategi kognitif, belajar teknik pembelajaran, dan belajar sepanjang masa.

Self regulated learning menyangkut penerapan dari model umum regulasi dan regulasi diri (self regulation) dalam proses belajar. Ada empat asumsi self regulated learning yang dipakai Wolters dkk (2003:3) yaitu pertama aktif dan konstruktif, siswa sebagai partisipan yang aktif dalam konstruktif belajar, baik itu mengkonstruk pemahaman, tujuan, maupun strategi dari informasi yang tersedia di lingkungan dan pikirannya sendiri. Kedua, self regulated learning sebagai potensi untuk mengontrol. Siswa sanggup memonitor, mengontrol, meregulasi aspek tertentu dari kognitif, motivasi dan perilaku sesuai karakteristik lingkungan jika memungkinkan. Ketiga, asumsi tujuan, kriteria atau standar. Asumsi tersebut digunakan untuk menilai apakah proses harus dilanjutkan bila perlu ketika beberapa kriteria atau standar berubah. Keempat, asumsi bahwa aktivitas dalam self regulated learning merupakan penengah (mediator) antara personal dan karakteristik konteks dan prestasi atau performa yang sesungguhnya. Self regulation pada kognitif, motivasi, dan perilaku yang dimiliki individu, merupakan perantara hubungan antar individu, konteks dan bahkan prestasi.

Selain faktor internal yang dijabarkan di atas faktor sekolah, kualitas sekolah sangat mempengaruhi prestasi sekolah siswa. Sekolah menengah atas yang baik memiliki atmosfer yang baik dan tidak oppresive, kepala sekolah yang aktif dan energik serta guru sekolah yang bijaksana dalam pengambilan keputusan. Kepala sekolah dan guru memiliki harapan yang tinggi pada siswa, lebih menekankan kegiatan akademik ketimbang aktivitas ekstrakurikuler dan memonitor dengan seksama performa siswa, Linney dan Seidman (dalam Papalia, 2011:573).

Siswa dituntun untuk dapat belajar secara optimal dan mandiri, dapat mengatur waktu dengan baik di sekolah serta melaksanakan kegiatan pembelajaran yang intensif sehingga siswa menjadi produktif, kreatif dan inovatif. Bekal utama yang dibutuhkan siswa untuk menyesuaikan diri dengan tuntutan tersebut adalah memiliki kemampuan dan keterampilan untuk mengatur kegiatan belajar, mengontrol perilaku belajar, mengetahui tujuan, arah, serta sumber-sumber yang mendukung untuk belajarnya. Namun nyatanya masih ada siswa kurang memahami cara belajar yang baik, sehingga banyak siswa belum memperoleh prestasi belajar yang sesuai dengan tuntutan sekolah. Agar tujuan pendidikan ini dapat tercapai maka diperlukan adanya kesadaran siswa untuk dapat memanfaatkan waktunya dengan baik dalam belajar.

Senada dengan hal tersebut penelitian yang dilakukan oleh Blair dan Razza (dalam Bodrova dan Leung, 2008) menemukan, perilaku meregulasi diri pada anak sejak usia dini dapat memprediksi prestasi sekolahnya dibandingkan skor IQ-nya. Weinstein \& Mayer (Basuki, 2005) menemukan, siswa yang mampu memberdayakan strategi-strategi self regulated learning, khususnya strategi kognisi dan metakognisi akan menghasilkan prestasi akademik yang lebih tinggi dibandingkan siswa yang tidak mampu memberdayakannya. Sungur dan Gungoren (2009) menemukan bahwa lingkungan sekolah yang mendorong siswa untuk meregulasi diri berpengaruh positif terhadap prestasi akademik. Berdasarkan kesimpulan yang diperoleh, dapat dijabarkan bahwa individu akan memperoleh hasil belajar yang baik, jika memiliki regulasi diri yang baik. Fenomena ini mengindikasikan bahwa, masih ada siswa belum memiliki kemampuan dan keterampilan untuk meregulasi dirinya dalam belajar dengan baik, yang kemungkinan berpengaruh terhadap rendahnya hasil belajar mereka.

Fakta yang ditemukan kurangnya pengetahuan siswa mengenai cara yang efektif dalam meregulasi diri dikarenakan kurangnya pemberian informasi mengenai cara pengaturan diri yang baik dalam belajar. Upaya mengatasi masalah tersebut sebenarnya telah dilakukan oleh guru dengan memberikan layanan belajar kelompok di sekolah tetapi hasilnya belum efektif dan perilaku siswa dalam aktivitas belum mencerminkan kemandirian.

Hasil penelitian yang dilakukan oleh Mochamad Anwar (2013) tentang Peningkatan Intensitas Belajar Mandiri dengan Layanan Informasi Di Kelas menunjukan pembekalan Layanan Informasi dapat meningkatkan intensitas siswa yang mandiri dalam aktivitas belajar yaitu 3 orang atau 25\% pada siklus I, meningkat menjadi 9 orang atau 75\% pada siklus II. Selanjutnya berdasarkan hasil penelitian dari Antono (2012) mengenai Kontribusi Layanan Informasi Bimbingan Belajar dan Kecerdasan Emosional terhadap Kemandirian Belajar 
siswa kelas VIII MTs AL Uswah Kabupaten Semarang Tahun Pelajaran 2008/2009, ditemukan setiap kenaikan satu unit skor layanan informasi dalam bidang bimbingan belajar dan satu unit skor kecerdasan emosional secara bersama-sama akan menaikkan kemandirian belajar siswa. Besarnya varian kemandirian belajar siswa yang ditentukan oleh layanan informasi dalam bidang bimbingan belajar dan kecerdasan emosional adalah 42,8\%.

Adanya pemberian layanan informasi diharapkan siswa memiliki pengetahuan tentang bagaimana cara belajar yang baik, disiplin diri yang baik, pemantapan penguasaan materi pelajaran, mencapai prestasi belajar secara optimal, memiliki penilaian diri yang maksimal serta dapat meningkatkan motivasi belajarnya. Berkaitan dengan itu Prayitno (1999:76) bahwa layanan informasi bertujuan untuk membekali individu dengan berbagai pengetahuan dan pemahanan tentang berbagai hal yang berguna untuk mengenal diri, merencanakan dan mengembangkan pola kehidupan sebagai pelajar, anggota keluarga dan masyarakat. Pemahaman yang diperoleh melalui layanan informasi digunakan sebagai bahan acuan dalam meningkatkan kegiatan dan prestasi belajar, mengembangkan cita-cita, menyelenggarakan kehidupan sehari-hari dan mengambil keputusan.

Berdasarkan uraian di atas banyak fenomena yang terjadi terkait pengaturan diri dalam belajar pada siswa, maka peran bimbingan dan konseling sangatlah penting dalam meningkatkan pengaturan diri dalam belajar (self regulated learning) pada siswa. Sebagai tindak lanjut dari fenomena yang ditemui, dalam upaya meningkatkan pengaturan diri dalam belajar (self regulated learning) dapat dilakukan dengan berbagai macam strategi. Layanan informasi merupakan salah satu jenis layanan bimbingan dan konseling yang memungkinkan siswa mengembangkan diri berkenaan dengan sikap dan kebiasaan belajarnya, serta dapat meningkatkan regulasi diri siswa. Oleh sebab itu peneliti tertarik untuk mengembangkan layanan informasi dengan movie maker untuk meningkatkan pengaturan diri dalam belajar (self regulated learning) pada siswa.

\section{Permasalahan}

Masalah pengaturan diri dalam belajar (self regulated learning) pada siswa sering ditemukan yang mana akan berdampak pada hasil belajar siswa. Masalah yang ditemukan berkaitan dengan pengaturan diri dalam belajar pada siswa adalah sebagian siswa kurang memiliki kemampuan dalam melakukan perencanaan, pengontrolan dan evaluasi dalam belajarnya sendiri, sebagian siswa kurang mandiri dalam belajar, kurang paham terhadap kemampuan dirinya sendiri terlihat dari kurang tekun dan optimal dalam belajar terlihat dari masih adanya siswa yang menyontek, masih ada siswa yang sering melalaikan tugas yang diberikan guru dan kurang disiplin dalam mengatur waktu belajar terlihat dari adanya siswa yang terlambat masuk kelas. Kesemua hal tersebut akan mempengaruhi hasil belajar siswa, oleh karena itu dibutuhkan perhatian dari para guru, khususnya guru BK dalam memberikan layanan salah satunya layanan informasi yang mana masih kurangnya pemanfaatan layanan informasi dengan media dan teknik yang menarik dari guru bimbingan dan konseling mengenai cara pengaturan diri yang baik dan efektif dalam belajar pada siswa.

\section{Pembahasan}

Zimmerman (dalam Winda, 2012:54) mengatakan self regulated learning dapat diajarkan, dipelajari dan dikontrol. Umumnya, siswa yang berhasil adalah siswa yang menggunakan strategi self regulated learning dan sebagian besar sukses di sekolahnya. Self regulated learning mampu mengatur kinerja dan prestasi akademis. Self regulated learning penting untuk diteliti, mengingat siswa harus mengatur diri supaya prestasi akademisnya sesuai dengan yang diharapkan.

Siswa yang belajar dengan regulasi diri bukan hanya tahu tentang apa yang dibutuhkan oleh setiap tugas, tetapi mereka juga dapat menerapkan strategi yang dibutuhkan. Mereka dapat membaca secara sekilas ataupun secara seksama. Mereka dapat menggunakan berbagai strategi ingatan atau mengorganisasikan materinya. Ketika mereka menjadi lebih knowlegeable (memiliki/menunjukkan banyak pengetahuan, kesadaran, 
atau inteligensi) di suatu bidang, mereka menerapkan banyak strategi secara otomatis. Alhasil, mereka telah menguasai sebuah strategi dan taktik pembelajaran yang besar dan fleksibel (Wooolfolk, dalam Eva 2010:113).

Pengaturan diri (self regulated learning) dibutuhkan siswa agar mereka mampu mengatur dan mengarahkan dirinya sendiri, mampu menyesuaikan dan mengendalikan diri, terutama bila menghadapi tugastugas yang sulit. Melalui pengaturan diri ini individu dapat memahami dan melakukan berbagai upaya-upaya yang ia dapat lakukan guna memperoleh tujuan belajar yang diharapkan.

Pengaturan diri dalam belajar yang baik menentukan kesuksesan seorang individu baik dari segi akademik. Aspek pengaturan diri dalam belajar diasumsikan dapat berkembang secara positif apabila diberikan perlakuan berupa layanan informasi. Pelaksanaan layanan informasi melalui media teknologi informasi ini diberikan dalam format klasikal.

Pelaksanaan layanan informasi dengan movie maker yang direncanakan akan menggunakan materi yang menjurus pada usaha peningkatan pengaturan diri dalam belajar, sehingga dapat membantu kesuksesan hasil belajar siswa di sekolah

\section{Penutup}

Umumnya, siswa yang berhasil adalah siswa yang menggunakan strategi self regulated learning dan sebagian besar sukses di sekolahnya. Self regulated learning mampu mengatur kinerja dan prestasi akademis. Self regulated learning penting, mengingat siswa harus mengatur diri supaya prestasi akademisnya sesuai dengan yang diharapkan.

Siswa yang belajar dengan regulasi diri bukan hanya tahu tentang apa yang dibutuhkan oleh setiap tugas, tetapi mereka juga dapat menerapkan strategi yang dibutuhkan. Mereka dapat membaca secara sekilas ataupun secara seksama. Mereka dapat menggunakan berbagai strategi ingatan atau mengorganisasikan materinya. Ketika mereka menjadi lebih knowlegeable (memiliki/menunjukkan banyak pengetahuan, kesadaran, atau inteligensi) di suatu bidang, mereka menerapkan banyak strategi secara otomatis. Alhasil, mereka telah menguasai sebuah strategi dan taktik pembelajaran yang besar dan fleksibel.

Hendaknya pelaksanaan layanan informasi dengan media movie maker ini dapat lebih diintensifkan dan diutamakan baik dalam bentuk orientasi dan sosialisasi maupun implementasi ke dalam bentuk program di sekolah. Oleh karena itu perlulah peran serta yang aktif dari kepala sekolah, konselor sekolah, serta siswa. Temuan ini dapat menjadi masukan bagi semua pihak yang terlibat dengan proses pendidikan baik di sekolah maupun di luar sekolah (orangtua) karena dengan perhatian kedua belah pihak akan menjadikan siswa sebagai individu yang percaya diri dan matang, serta mandiri dalam mempersiapkan masa depannya

\section{Daftar Pustaka}

Antono. (2012). “Kontribusi Layanan Informasi Bimbingan Belajar Dan Kecerdasan Emosional Terhadap Kemandirian Belajar”. Jurnal Bimbingan Konseling. (online), Vol. 01. No. 01. Hal: 9-13. (http://journal.unnes.ac.id/sju/index.php/jubk, diakses 05 Juli 2014)

Basuki, A.M.H. (2005). Pengujian Kontribusi Belajar yang Bemakna Pada Kreativitas, Self Regulated Learning, dan Prestasi Akademik: Studi Kasus Pada Siswa Sekolah Menengah Umum di Dakarta. Seminar Nasional PESAT. Jakarta: Universitas Gunadarma, 23-24 Agustus.

Bodrova, E. dan Leong, D.J. (2008). "Developing Self-Regulation in Kindergaten". Beyond The Journal. $\begin{array}{llll}\text { NAECSinState Departement } & \text { Of } & \text { Education, } & \text { (online) } \\ \text { (http://www.Journal.naeyc.org/btj200803/pdf/BTJPrimaryInterst, } & \text { diakses 13 Maret 2014). }\end{array}$ 
Eva, Latipah. (2010). “Strategi Self Regulated Learning dan Prestasi Belajar: Kajian meta analisis”. Jurnal Psikologi. Volume 37, No. 1, hal: 110 - 129. http://eprints.uinsuska.ac.id/4691/1/101791109200910441.pdf, diakses 25 Januari 2015).

Mochamad, Anwar. (2013). "Peningkatan Intensitas Belajar Mandiri dengan Layanan Informasi Di Kelas". Jurnal Ilmiah Pendidikan. (online), (http://eprints.uns.ac.id/4691/1/101791109200910441.pdf, diakses 05 Juli 2014).

Papalia, D.E., Olds, S. W., dan Feldman, R. D. (2001). Human Development. Eight Edition. New York: McGraw-Hill Company.

Prayitno. (1999). Dasar-dasar Bimbingan dan Konseling. Jakarta: Rineka Cipta.

Semiawan, C. (2000). Membuka Masa Depan Anak-anak Kita: Mencari Kurikulum Pendidikan Abad XXI. Yogyakarta: Kanisius.

Winda, Aufia. (2012). "Perbedaan Self Regulated Learning Ditinjau dari Status Kelas pada Siswa Kelas X Di SMA Negeri 1 Bukittinggi". Jurnal Ilmiah Pendidikan, (online), (http://jurnal.pendidikan/pdf, diakses 28 Januari 2015)

Wolters, C.A., Pintrich, P.R., dan Karabenick, S.A. (2003). Assesing Academic Self- Regulated Learning. Conference on Indicators of Positive Development: Child Trends.

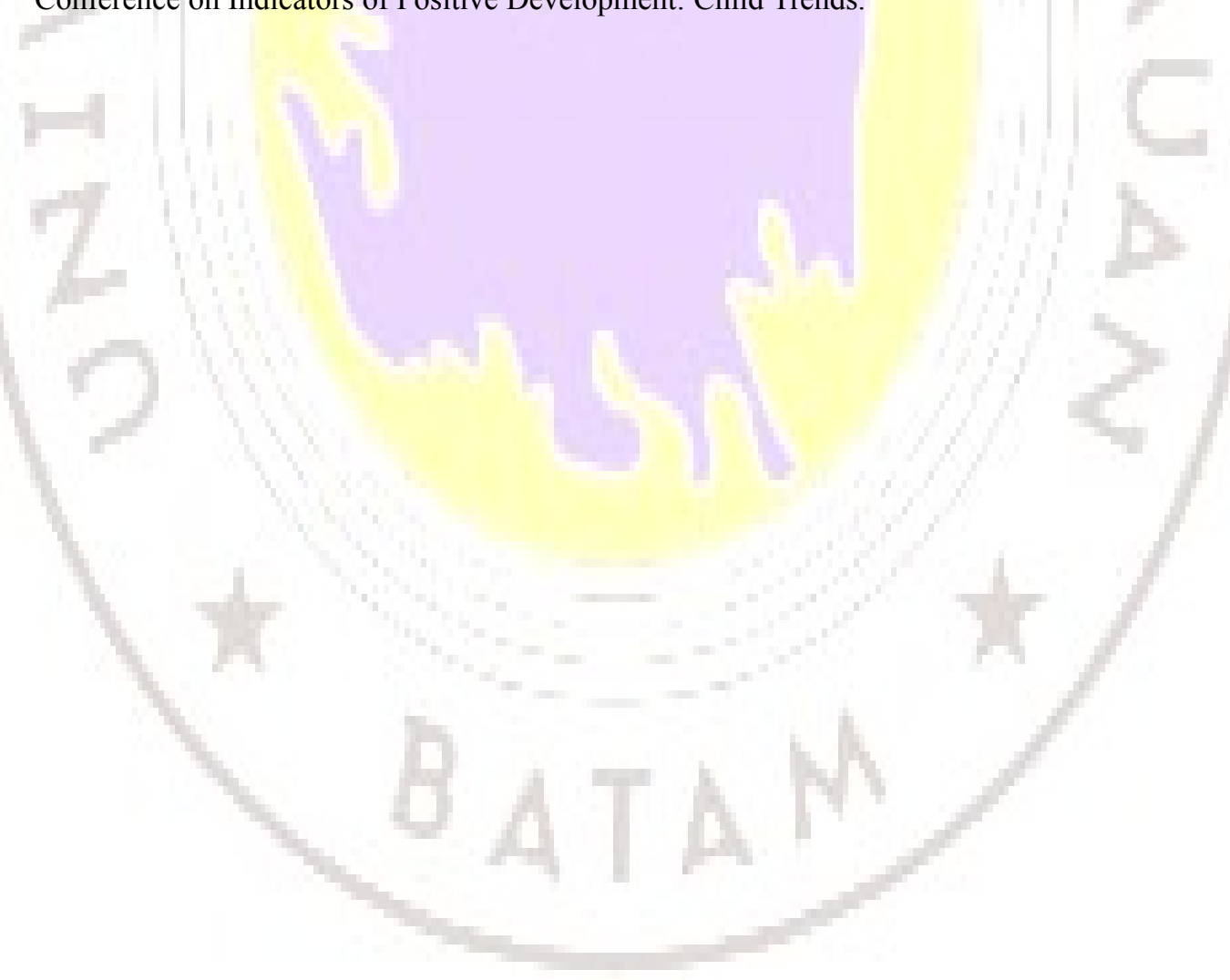

